\title{
AS DIMENSÕES MATERIAIS DA EFETIVIDADE DA JURISDIÇÃO AMBIENTAL ${ }^{1}$
}

\section{THE MATERIAL DIMENSIONS OF THE EFFECTIVENESS OF THE ENVIRONMENTAL JURISDICTION}

\author{
Paulo Marcio Cruz \\ UNIVALI - Universidade do Vale do Itajaí - Itajaí - Santa Catarina - Brasil \\ Zenildo Bodnar \\ UNIVALI - Universidade do Vale do Itajaí - Itajaí - Santa Catarina - Brasil
}

\begin{abstract}
RESUMO: $O$ presente artigo avalia criticamente 0 acesso à justiça e as dimensões materiais da efetividade da jurisdição ambiental na atual sociedade de risco. Para tanto, são analisados os princípios estruturantes da jurisdição ambiental, bem como são feitas reflexões sobre uma hermenêutica judiciária ambiental adequada à tutela dos bens ambientais e especialmente para a imputação de responsabilidade civil e para o controle dos comportamentos da Administração Pública. Conclui-se que a jurisdição ambiental deve estar fundamentada principalmente na solidariedade e na sustentabilidade e que a construção da decisão justa para o caso concreto requer uma visão sistêmica e holística, preocupação com o futuro e especial sensibilidade social e ambiental. Este artigo foi desenvolvido com a utilização do método indutivo.
\end{abstract}

PALAVRAS-CHAVE: Acesso à Justiça; Jurisdição Ambiental; Meio Ambiente.

ABSTRACT: This article critically evaluates the access to justice and the material dimensions of the effectiveness of the jurisdiction in the current environmental risk society. For this we analyzed the structural principles of juris-ing environment, and reflections are made on a judicial hermeneutics adequate environmental protection of the environmental goods and especially for the allocation of liability and to control the behavior-ment of Public Administration. It is concluded that the environmental jurisdiction must be based primarily on solidarity and sustainability, and that construction of the just decision for the particular case requires a systemic and holistic concern for the future and particular social and environmental sensitivity. This article was developed with use of the method inductive.

KEYWORDS: Access to Justice; Environment; Jurisdiction Environmental.

\footnotetext{
${ }^{1}$ Artigo desenvolvido no âmbito do Projeto de Pesquisa CNJ Acadêmico denominado "Juizados Especiais, Turmas Recursais e Turmas de Uniformização da Justiça Federal" com fomento do Conselho Nacional de Justiça (CNJ) e da Coordenação de Aperfeiçoamento de Pessoal de Nível Superior (CAPES). Também elaborado a partir das pesquisas efetuadas pelo Prof. Dr. Paulo Márcio Cruz durante estágio sênior na Universidade de Alicante, com bolsa CAPES.
} 


\section{INTRODUÇÃO}

$\mathrm{Na}$ atual quadratura da história, os cuidados especiais que o lar comum ou terra de todos necessita exigem contribuições qualificadas de todos os campos do saber humano e, em especial, daqueles que possam influenciar e melhorar as atitudes das pessoas em relação ao seu entorno.

O Direito enquanto não apenas técnica de controle, mas principalmente como instrumento de fomento e promoção de valores e de articulação global da solidariedade, deve participar ativamente desse grande desafio que é a sobrevivência da raça humana e sua demonstração de que pode conviver sustentavelmente com os outros seres vivos.

A melhora contínua dos comportamentos e atitudes humanas em relação ao meio ambiente, no contexto da atual sociedade de risco, depende de boas leis, instituições consolidadas e atuantes e intensa participação e controle social. Na perspectiva do campo do saber jurídico, há necessidade da produção de um bom Direito, materializado por intermédio de leis e decisões, e do aperfeiçoamento e qualificação das instituições, em especial do Poder Judiciário dos países em geral.

A crise ecológica é multidimensional, diz respeito não apenas à progressiva diminuição de bens e serviços ambientais, mas principalmente retrata uma crise de valores e de vínculos entre as pessoas e a natureza. Falta uma sensação geral de pertencimento e dependência mútua, bem como uma sensibilização profunda no sentido de que todos podem cooperar ativamente e fazer a diferença na melhora contínua das condições gerais de vida no planeta.

$\mathrm{O}$ desenvolvimento global e qualitativo, aliado à proteção efetiva do meio ambiente, constitui um dos grandes desafios para as sociedades contemporâneas. Estabelecer as diretrizes sustentáveis para um futuro com mais prudência ambiental e com a gestão adequada dos riscos é uma das principais tarefas do Direito Ambiental e, por consequência, da jurisdição ambiental.

Os obstáculos para o acesso pleno e efetivo à Justiça Ambiental apresentam-se com múltiplas dimensões e com uma ordem de complexidade 
peculiar. E por isso constata-se também uma crise geral e profunda tanto no acesso à justiça como na efetividade da jurisdição ambiental. Crise esta que decorre principalmente da falta uma racionalidade jurídica e uma hermenêutica dotada de especial sensibilidade ecológica; operacionalmente versátil para a outorga de um adequado tratamento aos conflitos envolvendo relações jurídicas amplas e complexas, nas quais estão envolvidos não apenas seres humanos, mas também toda a comunidade de vida e as futuras gerações.

A partir dessas preocupações é que estas reflexões são desenvolvidas, tendo como foco ou linha condutora central, a jurisdição ambiental e sua atuação num cenário desafiante de complexidade e risco. O objetivo geral foi o de abordar questão do acesso à justiça e seus fundamentos materiais que possam efetivamente contribuir qualitativamente com o desenvolvimento da prestação jurisdicional voltada à tutela do bem ambiental.

Procurou-se realizar reflexões críticas sobre o acesso à justiça ambiental priorizando-se, além do senso comum teórico que trata do acesso ao Poder Judiciário, aspectos diretamente relacionados com a efetividade de uma ordem jurídica ambiental justa e apta a fornecer respostas mais eficazes para as complexas questões do ambiente mundial globalizado.

Os princípios estruturantes da solidariedade e da sustentabilidade foram eleitos como as principais dimensões materiais que mais repercutem e contribuem na efetivação da jurisdição. Também são abordadas as necessidades de reflexões críticas quanto a uma hermenêutica judiciária ambiental, especialmente apta para a adequada imputação de responsabilidade por danos ao ambiente, gestão do risco e controle dos comportamentos da Administração Pública.

\section{O ACESSO À JUSTIÇA NA ATUAL SOCIEDADE DE RISCO}

A sociedade de risco apresenta importantes desafios para a jurisdição, principalmente por demandar uma nova racionalidade ${ }^{2}$ jurídica já que denuncia

\footnotetext{
${ }^{2}$ Muitos teóricos apresentaram contribuições históricas significativas para o desenvolvimento da teoria do conhecimento. Além das ponderações importantes de Emanuel Kant, na sua crítica a razão prática, merece destaque a racionalidade: a) "objetivo-científica" (Husserl); b) "conforme
} 
as limitações da dogmática tradicional e do saber isolado ou pertencente a um único campo do conhecimento humano.

O que infelizmente se constata na atual sociedade de risco ${ }^{3}$ é que o equilíbrio ecológico não será o mesmo, pois o mundo já atingiu os limites mais críticos e ameaçadores da sua trajetória. Estas ameaças decorrem do esgotamento dos recursos naturais não renováveis, da falta de distribuição equitativa dos bens ambientais, da configuração do crescimento exponencial da população, da pobreza em grande escala, do surgimento de novos processos tecnológicos excludentes alimentados pelo modelo capitalista. Todos estes fatores, portanto, resultam da consolidação de uma ética individualista e desinteressada no outro, no distante, nas futuras gerações, num desenvolvimento justo e duradouro.

Vive-se em tempos de mudanças profundas e em diversas perspectivas humanas: no ser, no pensar e no viver. O projeto de modernidade, baseado na razão kantiana, na liberdade, na igualdade formal e na infalibilidade da ciência, não só fracassou como também deixou para a atual geração um passivo importante de desigualdade material, insegurança e incerteza quanto ao futuro. É possível concluir, sem exageros fatalistas, que hoje se vive no mundo da exclusão social e na sociedade da explosão do risco ${ }^{4}$.

A sociedade de risco é a consequência ou o resultado do modelo de produção e consumo industrial baseado na maximização do lucro e no

resultado" (Weber); c) "técnico-estratégica" (Habermas), dentre outras contribuições. Todavia, a intensa evolução da sociedade, o aumento da sua complexidade e a multiplicação dos conflitos, requer novas formas de cognição e de gerenciamento científico dos problemas típicos da sociedade de risco. Em síntese: a sociedade de risco demanda o desenvolvimento de novos paradigmas de racionalidade que, sem excluir uma base axiológica consistente, possibilitem um conhecimento holístico e sistêmico das novas realidades e a construção de caminhos mais sólidos e seguros para o futuro.

${ }^{3}$ A partir dos relevantes contribuições de Ulrich Beck pode-se caracterizar a sociedade de risco como "[...] uma fase no desenvolvimento da sociedade moderna, em que os riscos sociais, políticos, econômicos e individuais tendem cada vez mais a escapar das instituições para o controle e a proteção da sociedade industrial". BECK, Ulrich. A reinvenção da Política: rumo a uma teoria da Modernização Reflexiva. In: BECK, Ulrich; GIDDENS, Anthony; LASH, Scott. Modernização reflexiva: política, tradição e estética na ordem social moderna. Trad. Magda Lopes. São Paulo: UNESP, 1997, p. 15. Apesar de serem reconhecidos os grandes méritos da teorização de Ulrich Beck, acerca da caracterização da sociedade de risco, deve-se advertir que a mesma apresenta limitações para a completa compreensão da relação entre os sistemas: natural e humano, pois as interações com o entorno (ambiente) dependem de um seria de fatores que envolvem fatores demográficos, capacidades e necessidades naturais e artificiais.

${ }^{4}$ Conforme defendido por GOLDBALTT, Dadid. Teoria Social do Ambiente. Lisboa: Piaget, 1996, p. 12 e ss. 
desenvolvimento a qualquer preço. Trata-se da consolidação de uma sociedade em situação periclitante de risco pluridimensional, onde a insegurança e a imprevisibilidade consubstanciam o componente básico e a única certeza decorrente das condutas humanas na atualidade.

O novo cenário é movediço, inspira cautela, requer atuação estratégica e antecipada. Porém, não é compatível com o imobilismo, ou seja, com a omissão. A convivência com situações de risco será uma constante no futuro da humanidade, gera um ambiente notabilizado pela insegurança e pela imprevisibilidade que requer um esforço também sinérgico e cumulativo de todos na sua gestão e controle a níveis de tolerabilidade. Deve ser entendido como alavanca propulsora ou chave que aciona a inteligência coletiva para atuar cooperativamente na definição dos destinos da humanidade.

Esse quadro desafiante gera um clamor generalizado por mais justiça ambiental, pois a distribuição dos bens e principalmente dos riscos e malefícios do desenvolvimento insustentável não mais acontece de maneira equitativa ${ }^{5}$.

$O$ acesso efetivo à Justiça Ambiental é um assunto que deve estar no centro das reflexões pela sua importância direta no que tange à consolidação de novos comportamentos e atitudes no que concerne ao ambiente. A plena garantia do acesso à Justiça Ambiental não diz respeito apenas ao aspecto procedimental, como conjunto de garantias e medidas para a facilitação do ingresso em juízo, mas também ao conteúdo dos provimentos jurisdicionais para a efetiva consecução da justiça na perspectiva social e ecológica, ou seja, ao acesso a uma ordem pública ambiental justa nas perspectivas difusa, transgeracional e global.

Um dos documentos internacionais muito importantes na temática do acesso à justiça é a Convenção de Aarhus ${ }^{6}$. Esta convenção influenciou decisivamente a legislação de acesso à informação na União Europeia e possui

${ }^{5}$ Esteve Pardo destaca a posição central do risco no âmbito das decisões políticas com repercussões intensas no Direito Público e no próprio papel do Estado e caracteriza como sociedade de risco o modelo pós-industrial da sociedade marcada pelo risco gerado pelo desenvolvimento tecnológico. ESTEVE PARDO, José. Técnica, riesgo e Derecho: tratamiento del riesgo tecnológico en el Derecho Ambiental. Barcelona: Ariel, 1999, p. 20 e ss.

${ }^{6}$ A Convenção da UNECE sobre Acesso à Informação, Participação do Público no Processo de Tomada de Decisão e Acesso à Justiça em Matéria de Ambiente (Convenção de Aarhus) foi adotada em 25 de Junho de 1998, na cidade dinamarquesa de Aarhus, durante a $4^{\text {a }}$ Conferência Ministerial "Ambiente para a Europa". Entrou em vigor em 30 de Outubro de 2001. 
instrumentos valiosos para a melhora da eficácia dos sistemas de justiça, especialmente por estar fundamentada no tríplice enfoque: informação, participação e acesso à justiça.

O qualificativo ambiental que se agrega ao princípio do acesso à justiça significa um redimensionamento no conteúdo e na abrangência deste postulado fundamental, exatamente em função do compromisso que deve assumir em prol da tutela efetiva do meio ambiente, inclusive com forte viés preventivo ${ }^{7}$.

O acesso à justiça ambiental também torna concreto o escopo político da jurisdição na medida que significa uma forma de exercício substancial de democracia e que permite ao cidadão o questionamento jurisdicional dos atos e omissões da Administração Pública, mediante o ajuizamento de Ações Populares Ambientais ou Ações Públicas por intermédio de associações e em benefício de toda a coletividade.

Ao fazer referência à segunda onda ou segundo grande movimento para melhorar o acesso à Justiça, Cappelletti e Garth (1988, p. 67) destacam que este movimento teve como objeto o problema da representação dos direitos difusos que, na concepção tradicional de processo civil, não possuíam espaço para proteção. As regras determinantes da legitimidade, as normas de procedimento e a atuação dos juízes não eram destinadas a facilitar as demandas por interesses difusos intentadas por particulares. Assim, buscou-se instrumentalizar o processo para assegurar também a tutela do meio ambiente. A terceira onda que os autores chamam de enfoque do acesso à Justiça apresenta uma perspectiva mais abrangente para o acesso à justiça, pois envolve o conjunto de instituições e mecanismos, pessoas e procedimentos utilizados para processar e mesmo para prevenir disputas nas sociedades modernas.

Na mesma linha que defende Herman Benjamin (1995, p. 71-72), o acesso à Justiça Ambiental, como direito fundamental do Estado Democrático, deve necessariamente contemplar as seguintes garantias: a) igualdade material, b)

\footnotetext{
${ }^{7}$ Fernanda Salles Cavedon, afirma que "acesso à Justiça pode, assim, ser identificado como acesso à prevenção e resolução de conflitos tendo como parâmetro o ideal de Justiça, correspondendo ao acesso à decisão justa e à garantia do exercício dos direitos ambientais inerentes à cidadania ambiental". In: CAVEDON, Fernanda Salles. Renovação do sistema jurídico-ambiental e realização do acesso à Justiça Ambiental pela atividade criadora no âmbito da decisão judicial dos conflitos jurídico-ambientais. Tese de Doutorado defendida junto à Universidade do Vale do Itajaí, 2006. p. 36.
} 
proteção efetiva dos riscos ilegítimos, inclusive potenciais; prevenção de litígios; educação ambiental (aspecto pedagógico); ampla participação dos cidadãos.

A partir desses importantes aportes doutrinários, constata-se que o acesso à Justiça Ambiental possui ampla significação e notável relevância. Trata-se de um mandamento geral cujo conteúdo centraliza um objetivo claro que pode ser traduzido na busca pela melhora contínua das relações dos seres humanos com a natureza.

A atual dimensão da crise ecológica requer um esforço global solidário e uma atuação exemplar dos Estados na consecução da verdadeira Justiça Ambiental. Nesse contexto, a garantia plena do acesso à justiça ambiental poderá desencadear um sentimento de clamor geral por justiça e uma exortação para que todos estejam engajados nesta causa que é da humanidade.

As constituições democráticas estabelecem um conjunto de garantias para assegurar formalmente amplo acesso à justiça ambiental. No Brasil, além da cláusula da inafastabilidade do controle jurisdicional em relação a qualquer ameaça ou lesão a direitos, a Constituição garante: a) a assistência judicial integral e gratuita aos necessitados; b) remédios constitucionais como: mandado de segurança coletivo, mandado de injunção coletivo, ação popular, amplos poderes e atribuição ao Ministério Público para atuar na defesa judicial e extrajudicial do meio ambiente, principalmente com a propositura da ação civil pública; c) um conjunto de princípios para o resguardo do devido processo legal substancial: isonomia entre as partes, contraditório, ampla defesa, duração razoável do processo, dentre outros.

Com isso as constituições em geral já estabelecem um sistema de garantias para assegurar o amplo acesso à Justiça Ambiental. Porém, o maior desafio é conferir efetividade social e concreta aos direitos fundamentais que justificaram o estabelecimento desse instrumental de garantias. Hoje, o maior desafio para o alcance da efetividade não está mais relacionado apenas com o aspecto superficial do acesso a justiça ${ }^{8}$ (custas e morosidade do processo, falta de tempo para os legitimados, barreiras psicológicas e culturais), mas sim com o acesso substancial à verdadeira Justiça. No aspecto substancial merecem

\footnotetext{
${ }^{8}$ Este aspecto diz até mais respeito ao acesso ao Poder Judiciário do que ao acesso à efetiva Justiça Ambiental. Embora qualificado como circunstância superficial também requer medidas para adequadas e não pode ser desconsiderado para uma prestação jurisdicional de excelência.
} 
destaque as dimensões materiais da efetividade.

A justiça ambiental não é algo pronto e acabado e que pode ser distribuído facilmente a todos. Trata-se de uma idealidade, de um horizonte de sentido dotado de uma utopia mobilizadora. Assim, não é correto falar-se em Justiça, mas sim em fazer-se Justiça como algo em permanente e contínua construção e que mobiliza a todos para essa luta.

Essa noção preliminar de justiça ambiental contempla uma força promocional dinâmica e exige o engajamento de todos na sua concretização, em especial do Poder Judiciário como guardião dos valores democráticos e dos bens intangíveis da coletividade global. Afinal, o Poder Judiciário que pode dar sentido concreto aos mandamentos normativos constitucionais e internacionais que tutelam o ambiente.

A realização de reformas legislativas pontuais ou a adoção singela de medidas isoladas pouco ajudará na efetividade da jurisdição ambiental, especialmente considerando que muitos países, como o Brasil, já possuem ordenamentos jurídicos ambientais bastante. É fundamental também que os parlamentos possam ter ampla compreensão do significado e alcance deste novo paradigma (CRUZ; BODNAR, 2011, p. 75-83), assim como uma sensibilização geral dos operadores jurídicos para este novo desafio.

\section{DIMENSÕES MATERIAIS DA JURISDIÇÃO AMBIENTAL}

A efetividade não está apenas na ampla acessibilidade aos mecanismos oficiais de resolução e tratamento dos conflitos, mas também na consecução plena das aspirações legítimas da coletividade por justiça, ou seja, no conteúdo material e na efetividade das decisões e medidas adotadas.

Como dimensões materiais que fundamentam e mais repercutem na efetividade da jurisdição, elegem-se os princípios estruturantes da solidariedade e da sustentabilidade. Também serão realizadas reflexões críticas sobre a necessidade de uma hermenêutica judiciária ambiental mais adequada para a imputação de responsabilidade por danos ao ambiente, gestão do risco e controle dos comportamentos da Administração Pública. 


\subsection{Princípios estruturantes da jurisdição ambiental: solidariedade e sustentabilidade}

A crise atual não é apenas ecológica, é também uma crise de valores e de vínculos, reflexo da desvinculação progressiva de uma racionalidade axiológica em direção à razão técnica que muitas vezes distancia e desvincula os seres humanos da natureza na busca obstinada do desenvolvimento a qualquer custo. Este quadro de patologia social deve ser apreendido e compreendido na atividade construtiva e transformadora da jurisdição ambiental.

É nesse contexto que surge a preocupação científica com o desenvolvimento teórico dos princípios fundamentais que devem inspirar, orientar e promover todo o impulso construtivo e pedagógico a ser protagonizado pela jurisdição ambiental.

$\mathrm{Na}$ atual sociedade de risco, a imprescindível atividade político-jurídica da jurisdição somente produzirá resultados efetivamente consequentes se estiver fundamentada nos princípios da solidariedade e da sustentabilidade.

Importante tratar, inicialmente, da solidariedade, em suas múltiplas dimensões, como um dos princípios que funcionam, atualmente, como elementos para a construção de ordenamentos jurídicos transnacionais. O princípio da solidariedade possibilita ampla juridicização, principalmente por intermédio da doutrina e das decisões dos Poderes Judiciários ${ }^{9}$.

Um dos desafios da jurisdição, enquanto tarefa pública estratégica é o de contribuir para que a tutela do meio ambiente encontre o seu adequado fundamento a partir da aplicação do princípio da solidariedade, o que poderá ser decisivo para a construção de uma teia da vida global.

A proteção do ambiente é um dever fundamental imposto não apenas aos estados, mas também a todos os cidadãos. Este dever fundamental exige de todos um agir solidário em prol da proteção da natureza, implica também o ônus imposto a todos de participar ativamente das decisões e encaminhamentos

\footnotetext{
${ }^{9}$ Martín Mateo destaca que a solidariedade é um condicionamento, não só de elementares considerações morais, mas condição para o desenvolvimento sustentável, sob pena de os nossos descendentes terem dificuldades progressivas para assimilar o legado ambiental e os riscos sociais que Ihes transmitiremos. MARTÍN MATEO, Ramón. La revolución ambiental pendiente. In: PIÑAR MAÑAS, José Luis. Desarrollo Sostenible y protección del medio ambiente. Civitas: Madrid, 2002. p. 57.
} 
relacionados ao interesse geral de um ambiente sadio e equilibrado.

Parte essencial dessa nova revolução é a emergência e consolidação de um novo conceito de cidadania: aquela cujo referente não é, como o foi até agora, o Estado Constitucional Moderno, mas sim o planeta como território e a humanidade como sociedade solidária. (REAL FERRER, 2011, p. 45)

A solidariedade, enquanto princípio jurídico estruturante pode ser o marco referencial axiológico para a consolidação de uma nova ética para o homem tecnológico insensível. Trata-se do fundamento basilar dos deveres fundamentais, especialmente os deveres ecológicos. A solidariedade constitui uma importante estratégia para o estabelecimento de vínculos consistentes com o futuro e assegurar a proteção das futuras gerações.

A solidariedade contempla um substrato ético, enquanto valor fundamental para a organização e para a harmonia das relações entre os seres humanos, o entorno e o porvir. A eticidade não compreende só leis, instituições e conceitos éticos, mas também concepções, princípios ou ideais de vida que dão sustentáculo às leis, instituições e conceitos e que se vinculam a uma cultura (COLL, 2001, p. 05 e ss).

Em julgamento histórico o Supremo Tribunal Federal do Brasil reconheceu a importância do dever de solidariedade, enquanto valor estruturante dos direitos de terceira dimensão, mais especificamente do ambiente. Nesta decisão o Ministro Celso de Melo foi enfático ao afirmar que o meio ambiente é direito de todos e especial obrigação do Estado e da coletividade e que o adimplemento desse encargo, que é irrenunciável, representa a garantia de que não se instaurarão, no seio da coletividade, os graves conflitos intergeneracionais marcados pelo desrespeito ao dever de solidariedade, que a todos se impõe, na proteção desse bem essencial de uso comum das pessoas em geral. (BRASIL. Supremo Tribunal Federal. Medida Cautelar na Ação Direta de Inconstitucionalidade 3540)

A partir da solidariedade surge também o princípio da sustentabilidade como princípio decorrente, interligado e complementar e que completa a sólida estrutura fundacional da jurisdição na dimensão material garantista. A sustentabilidade é aqui também analisada enquanto princípio jurídico e compreendida a partir de suas dimensões ecológica, social, econômica e 
tecnológica e como um imperativo ético tridimensional, implementado em solidariedade sincrônica com a geração atual, diacrônica com as futuras gerações $^{10}$, e em solidária sintonia com natureza, ou seja, em benefício de toda a comunidade de vida e com os elementos abióticos que lhe dão sustentação.

A nota qualitativa da sustentabilidade, preconizada também como intento motivador da (Eco-92), ainda não foi viabilizada na sua integralidade, pois o paradigma de desenvolvimento vigente em escala global está pautado muito mais na lógica da maximização dos lucros e da "liberdade" de mercado do que na preocupação ética de distribuição geral e equitativa dos benefícios gerados pelo desenvolvimento.

Esse quadro desafiante impõe a necessidade não apenas de ações locais e isoladas, mas de uma especial sensibilização também globalizada, que contribua com a internalização de novas práticas e atitudes, principalmente nas ações dos Estados no plano mundial. São necessárias novas estratégias de governança transnacional ambiental ${ }^{11}$ para que seja possível a construção um compromisso solidário e global em prol do ambiente para assegurar, inclusive de maneira preventiva e precautória, a melhora contínua das relações entre os seres humanos e a natureza.

A preocupação da geração atual não deve ser a de apenas garantir às futuras gerações a mesma quantidade de bens e recursos ambientais. A insuficiência deste objetivo é manifesta. Isso porque a irresponsabilidade do ser humano gerou um desenvolvimento historicamente insustentável e já levou a

10 Edith B. Weiss, explica que o compromisso assumido no Rio para um desenvolvimento sustentável fui inerentemente integeracional e defende a tese de que cada geração recebe um legado natural e cultural como fideicomiso das gerações anteriores, para que por sua vez seja transmitida às futuras gerações. Esta relação impõe obrigações planetárias para cada geração e também brinda certas gerações com direitos também planetários. In: WEISS, Edith Brown. Un mundo Justo para las Futuras Generaciones: Derecho Internacional, Patrimonio Común y Equidad Integeracional. Trad. Máximo E. Gowland. Madrid: United Nations, Mundi-Prensa, 1999. p. 37,39 e 40 .

${ }^{11}$ Sobre este tema ver: BODNAR, Zenildo e CRUZ, Paulo Márcio. Pensar globalmente y actuar localmente: El Estado transnacional ambiental em Ulrich Bech. Revista Aranzadi de Derecho Ambiental, v. 1, n. 1, p. 51-59, 2008; e BODNAR, Zenildo; CADEMARTORI, Luiz Henrique Urquhart; CRUZ, Paulo Márcio. O estado transnacional ambiental em Ulrich Beck e suas implicações com o estado constitucional e a Administração Pública. Revista do IASP, n. 22, 2008. Nestes trabalhos, propõe-se a consolidação de um 'Estado Transnacional' de proteção do meio ambiente, estruturado como uma grande teia de proteção do planeta, regido por princípios ecológicos e que assegure alternativas e oportunidades democráticas mais inclusivas, participativas e emancipatórias e tenha como preocupação garantir um mundo melhor para as futuras gerações. 
atual geração à beira do colapso pela manifesta limitação de muitos bens primordiais para a vida plena. Assim, é fundamental que toda a inteligência coletiva e que todo o conhecimento científico acumulado estejam também a serviço da melhora das condições de toda a comunidade de vida futura e não apenas a serviço do ser humano.

$\mathrm{Na}$ obra jurídica mais completa da atualidade sobre o princípio da sustentabilidade, Klaus Bosselmann (2008, p. 79 e ss), defende enfaticamente a necessidade da sua aplicação enquanto princípio jurídico basilar da ordem jurídica local e internacional. Argumenta que o princípio da sustentabilidade deve contribuir com a ecologização dos demais princípios e, desde que devidamente impulsionado pela força real da sociedade civil, servirá também como caminho para uma governança com sustentabilidade ecológica e social.

$\mathrm{Na}$ sociedade hipercomplexa, globalizada e altamente influenciada pela racionalidade econômica, a sustentabilidade não é um dado, algo pronto, perfeito e plenamente conquistado. Trata-se de uma categoria ainda em fase de emancipação e consolidação e que necessita um agir construtivo e sinérgico de vários campos do saber humano.

Neste processo, destaca-se o papel da jurisdição ambiental no sistema jurídico, pois este deve assumir um protagonismo de liderança, no intuito de imprimir força jurídica, densificar com juridicidade posições discursivas que às vezes são meramente retóricas e ideológicas e outorgar a condição de um autêntico princípio jurídico fundamente para garantir a construção de um projeto revolucionário de civilização realmente mais justa, solidária e promissora.

Estes princípios estruturantes (solidariedade e sustentabilidade) requerem, por parte da jurisdição, base cognitiva holística e sistêmica. Holística pela necessidade da consideração de todas as variáveis (direitos e valores) envolvidos direta e indiretamente nos conflitos e sistêmica pela necessidade de identificação da função de cada uma das variáveis e da maneira e intensidade pela qual interagem para uma adequada valoração reflexiva. Em síntese: uma hermenêutica judiciária especializada. 


\subsection{Caminhos para nova hermenêutica judiciária ambiental}

A maioria das constituições ocidentais do pós segunda grande guerra, inclusive a brasileira de 1988, impõem ao Estado e à sociedade o dever de preservar e proteger o ambiente enquanto direito e dever fundamental. Ingo Sarlet $^{12}$ (2008, p. 142-143) enfatiza a perspectiva jurídico-objetiva dos direitos fundamentais e sua função como imperativos de tutela ou deveres de proteção do Estado. O Poder Judiciário, enquanto um dos poderes do Estado é também destinatário deste dever fundamental ${ }^{13}$.

Assim cabe aos magistrados, enquanto peças chaves para 0 aprimoramento da democracia, protagonizar em cada ato a transformação da sociedade, cada vez mais plural e diversificada no novo milênio. O magistrado idealista precisa acreditar que pode contribuir na mudança do mundo para melhor, abandonar a ética egoísta e disseminar ética solidária e ambientalmente adequada $^{14}$.

A jurisdição ambiental concentra um caráter pedagógico substancial, pois deverá servir como forma de educação. Confirme conclui Nalini (1998, p. 11) "o julgamento contém, subsidiariamente à solução da controvérsia à solução da controvérsia, um ensinamento".

Entretanto, como regra, a jurisdição é ainda exercida partindo-se de uma base de pensamento lógico-formal-dedutivista, da hierarquização de ideias e construída com argumentos piramidais de autoridade. Na escolha da norma ao

${ }^{12}$ Este autor, oferece consistentes subsídios doutrinários para a defesa da atuação do Poder Judiciário numa perspectiva substancial. Defender que mesmo considerando os limites fáticos é possível exercer o controle jurisdicional de políticas públicas principalmente para a plena efetividade da dignidade da pessoa humana.

${ }^{13}$ Conforme destaca Freitas, o juiz possui papel relevante por exercer um dos poderes da República "em nome do povo e tem por obrigação defender e preservar o meio ambiente para presentes e futuras gerações. FREITAS, Vladimir Passos de (Org.) Direito ambiental em evolução. Curitiba: Juruá, 1998, p. 29-30.

${ }^{14}$ Conforme destaca José Luis Serrano, à luz da ecologia política, um projeto ecointegrador pressupõe uma forte atribuição de responsabilidade ao Poder Judicial. SERRANO, José Luis. Principios de Derecho Ambiental e Ecología Jurídica. Madrid: Trotta, 2007. p. 88. A importância da sensibilidade social do julgador é destacada por Faria ${ }^{14}$, ao afirmar na resolução de conflitos sociais o juiz deve atuar como um 'arquiteto social', modificando as concepções discriminatórias da ordem jurídica vigente, valendo-se de suas sentenças como instrumentos, que auxiliem os grupos e as classes subalternas a se constituírem efetivamente como 'sujeitos coletivos de direito' In: FARIA, José Eduardo. Justiça e Conflito. Os juízes em face dos novos movimentos sociais. 2. ed. rev. e ampl. São Paulo: Revista dos Tribunais, 1992, p. 112. 
caso, utilizam-se singelos critérios de generalidade e especialidade. Há uma clara carência significativa do desenvolvimento da capacidade crítico-reflexiva para compreender o funcionamento também de outros sistemas e como estes interferem no mundo do direito.

A interpretação que é necessariamente histórica, contextual e criativa, não pode ser - e de fato não é - um "labor descompromissado", no qual se resolve a vida das pessoas apenas com trocadilhos de palavras. Também não poder representar um ato de rebeldia contra os poderes públicos como se estes fossem os únicos responsáveis por todas as mazelas existentes na sociedade.

$\mathrm{Na}$ construção da decisão adequada para o caso concreto o desafio hermenêutico da jurisdição não pode ser mais um singelo exercício de subsunção do fato à norma, mas sim uma intensa atividade de construção e ponderação, participativa e dialética, que considera os imprescindíveis aportes cognitivos transdisciplinares e que projeta cautelosamente os efeitos e as consequências da decisão numa perspectiva de futuro ${ }^{15}$.

Não há mais certeza ou segurança quanto à validade das premissas e muito menos, numa projeção futura, dos dados e variáveis que integram todo e qualquer processo de tomada de decisão envolvendo risco. Conforme destacam Morato Leite e Patrick Ayala (2002, p. 12 e ss) os riscos insustentáveis que decorrem de processos gerados em espaços institucionais com acentuados déficits democráticos e com potencial lesivo em uma escala espacial e temporal de difícil determinação.

Esse tipo de constatação ajuda a mostrar o esgotamento do modelo racionalista moderno que colocou a ciência no ápice do pedestal do saber, apta a dar respostas a todos os questionamentos humanos. Hoje, também a partir das teorias Freudianas da psicanálise, deve-se agir incluindo a sensibilidade numa parceria construtiva com a razão.

Luiz Alberto Warat (2010, p. 09) é enfático ao afirmar que os senhores invisíveis da globalização sabem que para conservar seu poder tem de construir a torre do pensamento único, globalizar ideias que não admitem a diversidade

\footnotetext{
${ }^{15}$ Marcelo Varella destaca que na decisão de risco as alternativas não estão mais entre o seguro e o inseguro, mas entre opções, com vantagens e desvantagens entre si. VARELLA. Marcelo Dias. A Dinâmica e a Percepção Pública de Riscos e a Resposta do Direito Internacional Econômico. In: VARELLA. Marcelo Dias (Org.). Governo dos Riscos. UNICEUB, Brasília, 2005.
} 
que seria a última versão do universalismo, a nova forma de assegurar a continuidade da razão abstrata. Essa homogeneidade destrutiva é a igualdade como um modelo artificial, o que impede qualquer tipo de sensibilidade ou empatia global que torne a convivência humana mais civilizada.

$\mathrm{Na}$ via da globalização, a política foi claramente ultrapassada pelos outros sistemas sociais, como escreve Gunther Teubner (2013, p. 13). A razão decisiva para que atualmente a produção normativa esteja se distanciando cada vez mais da política reside no fato de que o acoplamento do sistema político e do sistema jurídico por meio de constituições não conta com uma instância correspondente no plano da sociedade mundial. E, como se sabe, a economia produz a riqueza e a política trata de distribuí-la. Sem uma política transnacional será impossível distribuir a riqueza transnacional. Torná-la instrumento de desenvolvimento social efetivo.

A ideia historicamente consolidada de um Direito baseado na completude, coerência e não contradição, já não é mais suficiente para a gestão do risco. $A$ crise contemporânea do Estado de direito e da justiça requer também a reformulação do pensamento jurídico com a superação dialética do paradigma moderno $^{16}$. E deve-se anotar que não pode haver, a partir do novo paradigma pós-moderno, espaços para a miserabilidade consentida ou imposta. (FREITAS, 2011, p. 56)

Conforme destacam Bodnar e Cruz (2010, p. 432-446) o compromisso do Direito não mais se resume a garantir âmbitos de liberdade e a equacionar a igualdade formal entre os seres humanos. Não há mais previsibilidade nas ações e comportamentos e nem certezas quanto aos fatos e variáveis intervenientes nos processos de tomada de decisão, ou seja, necessita-se do imprescindível aporte de outros saberes para bem compreender os problemas e para gerir de forma consequente o futuro. Afinal, A finalidade da norma, tanto a editada pelo legislador como a criada para o caso concreto pela jurisdição, ainda tem sido

${ }^{16}$ ARNAUD, André-Jean. Entre modernité et mondialisation: Leçons d'histoire de la phisosophie du droit et de l'État. 2. ed. Paris: L.G.D.J, 2004. p. 238 e ss. Este autor também apresenta um interessante quadro apontando os contrastes entre o direito da modernidade e o da pós modernidade: 1. abstração $\mathrm{x}$ pragmatismo; 2.subjetivismo $\mathrm{x}$ descentralização do sujeito; 3 . Universalismo $\mathrm{x}$ relativismo; 4. unidade da razão $\mathrm{x}$ pluralidade das razões; 5 . Axiomatização $\mathrm{x}$ lógicas variadas e ecléticas; 6 . Simplicidade $x$ complexidade; 7 . separação entre Estado e sociedade civil $\mathrm{x}$ retorno à sociedade civil; 8 . Segurança $\mathrm{x}$ risco. 
predominantemente a imposição coercitiva de comportamentos, os quais também produzem alterações no entorno e novas situações de risco sistemático e sinérgico. Isso tanto na perspectiva ecológica como também cultural. Nesse agir comunicacional reflexo, e também considerando a dinâmica dos fatos e a velocidade dos acontecimentos, haverá provavelmente uma defasagem contínua da norma idealizada quer seja pelo legislador ou pelo julgador.

Nesse contexto, incumbe ao Direito e, por consequência a jurisdição, a tarefa de qualificar axiologicamente o agir humano não apenas na perspectiva do comportamento responsável intersubjetivo e comunitário, mas também enquanto um compromisso ético alargado, exercido a longo prazo, tanto em benefício e atenção das futuras gerações como também de toda a comunidade de vida.

O campo de atuação da hermenêutica judiciária ambiental caracteriza-se, não apenas pela intensidade das colisões, mas pela quantidade de direitos fundamentais implicados, circunstâncias estas que também exigem especialização, ou seja, o desenvolvimento de uma hermenêutica própria.

Na perspectiva ou dimensão material a construção da justiça para o caso concreto, exigirá critérios de ponderação abrangentes, ancoragem constitucional e sensibilidade para os bens com ampla repercussão planetária e de suporte da vida. Todas as variáveis intervenientes devem ser criteriosamente sopesadas e avaliadas, o instrumental técnico do Direito não pode prescindir do aporte de outros campos do saber e nem do forte substrato ético subjacente aos litígios ${ }^{17}$.

O aspecto subjetivo, ou seja, a quantidade de interessados e as consequências de longo prazo de qualquer atividade interpretativa exigem

\footnotetext{
${ }^{17}$ Nos casos que envolvem colisões entre interesse ambiental e outros direitos fundamentais, a jurisprudência italiana, especialmente nas decisões da Corte Constitucional, o balanceamento é feito na tentativa de conciliar os diversos interesses envolvidos, por intermédio de uma mediação que busca estabilizar a ação dos poderes públicos ou integrar o dissenso no sistema político ou então através de um procedimento lógico que avalia a escolha legislativa à luz dos valores constitucionais envolvidos". CORDINI, Giovanni. Diritto Ambientale Comparato. Padova: CEDAM, 1997, p. 86 e 87. Michel Prieur defende também que o Juiz deve aplicar o princípio da proporcionalidade considerando a importância ou proporção da obra ou da importância 'a priori' da obra para o ambiente. PRIEUR, Michel. O Direito do Ambiente na França. In AMARAL, Diogo Freitas; ALMEIDA, Márcia Tavares (Coords.). Direito do Ambiente. Lisboa: INA Instituto Nacional de Administração. 1994. p. 282. Quanto não é possível encontrar um ponto de equilíbrio, o Tribunal Constitucional Espanhol, tem utilizado: a) Juízo de razoabilidade - aferição da existência de um fim constitucionalmente legitimo para a administração restringir a atividade particular; b) Princípio da proporcionalidade - relação entre as medidas adotadas e os fins perseguidos. In: CUTANDA LOZANO, Blanca. Derecho Ambiental Administrativo. 7. ed. atual. Madrid: Dykinson, 2006. p. 93-94.
} 
especial consideração do julgador. Não se trata de não levar a sério o indivíduo, como reivindica Alexy $^{18}$, mas sim de não esquecer a sociedade no seu conjunto, as futuras gerações e toda a comunidade de vida e, por consequência, garantir ao próprio indivíduo as melhores condições de vida presente e futura.

Um dos direitos fundamentais de feição predominantemente individualista que mais entra em rota de colisão com o ambiente é o direito de propriedade. $\mathrm{Na}$ colisão entre o direito de propriedade e o ambiente, é importante o julgador fazer opções conscientes, responsáveis e criativas que, sem aniquilar o núcleo essencial da propriedade, preservem a intangibilidade do ambiente. Não se trata de estabelecer uma tirania apriorística de valores em prol do ambiente, mas de uma opção consciente que deve necessariamente prestigiar um bem de toda a comunidade de vida atual e futura. Afinal, enquanto os bens patrimoniais podem ser renovados/reconquistados/vendidos e não geram direitos imediatos para as futuras gerações (herdeiros), os bens ambientais pertencem a toda comunidade de vida, atual e futura.

Essa análise é necessária quando o tema envolve a adequada atribuição de responsabilidade por danos ao ambiente, pois esta é uma das dimensões materiais mais significativas da jurisdição ambiental que requer constante aperfeiçoamento para o alcance da necessária efetividade.

$\mathrm{Na}$ atividade de cognição, a ser exercida pelo magistrado no momento da avaliação dos danos, deverão ser analisados criteriosamente não apenas os danos, mas principalmente o comportamento lesivo. A realização substancial da justiça, na perspectiva preventiva e com propósitos de uma justiça que transcendem ao caso concreto, deve objetivar exatamente a melhora contínua do comportamento humano em relação à natureza numa perspectiva de futuro e não

${ }^{18}$ Ao contrário de Dworkin, que no caso de colisão frente a direitos coletivos, atribui caráter essencialmente definitivo aos direitos, Alexy explica que os direitos apresentam caráter de mandados de otimização, assim não são direitos definitivos, senão direitos prima facie que, quando entram em colisão com bens coletivos ou direitos de outros podem ser restringidos. Alexy sustenta inclusive a precedência prima facie dos direitos individuais na relação com bens coletivos, porém reconhece importantes objeções que são opostas a essa concepção individualista, a qual evidentemente não é minimamente satisfatória para uma análise de colisão entre os direitos de solidariedade ou de terceira dimensão com os interesses de feição individualista. A teoria da argumentação desenvolvida por Alexy, dentre outros, apresenta inegáveis contribuições para a ponderação de direitos no caso concreto. Todavia, foi concebida e estruturada ainda muito mais voltada para colisões entre direitos e interesse de mesma dimensão subjetiva. In: ALEXY, Robert. El concepto y la validez del derecho. 2. ed. Barcelona: Gedisa, 1997, p. 185 e ss. 
apenas numa focalização da análise dos danos já consumados e muitas vezes irreversíveis, ou seja, deve-se julgar com os olhos voltados para o futuro e não apenas para o histórico de fracasso do passado ${ }^{19}$.

A adequada gestão do risco, bem como a imputação de responsabilidade sem dano (dano futuro, provável), somente será possível com a atuação focada no comportamento. Com este novo enfoque, aumenta-se a efetividade da tutela preventiva e possibilita-se até mesmo a responsabilização ambiental quando o mero comportamento já enseja riscos graves e intoleráveis ao ambiente. $O$ julgamento que valoriza a análise da conduta lesiva também não está sujeito à erosão de efetividade ocasionada pela natural dificuldade e complexidade, no campo probatório, da demonstração dos nexos de causalidade entre o fato e o dano.

Além da imputação adequada e suficiente de responsabilidade e da gestão do risco, um dos desafios qualificados para a jurisdição ambiental é o controle dos atos dos poderes públicos, comissivos ou omissivos.

A importante missão de completar e reconhecer novos direitos, ampliando os espaços de cidadania, caracteriza o fenômeno da judicialização da vida social. O Poder Judiciário, enquanto poder político desempenha um papel proeminente na salvaguarda de direitos e garantias fundamentais e de socorro aos mais fragilizados.

$\mathrm{Na}$ perspectiva da jurisdição ambiental, a incumbência constitucional atribuída aos Estados para a defesa e proteção do meio ambiente, já há vinte anos, ainda não foi atendida sequer minimamente. São inúmeras as omissões do Poder Público que acontecem nas mais diversas políticas públicas, políticas estas que deveriam ser implementadas para a garantia da qualidade do meio ambiente. Ainda falta saneamento básico, educação ambiental, estrutura para os órgãos de fiscalização e licenciamento dentre outras carências. Este quadro contribui decisivamente com a crise ecológica generalizada e exige uma intervenção mais enérgica e eficaz por parte do Poder Judiciário. Justifica essa intervenção.

Considerando a amplitude dos deveres ecológicos estatuídos em âmbitos

\footnotetext{
${ }^{19}$ Qualquer ação que objetiva a reparar danos já consumados é, de certo modo, uma história de fracasso, pois indica a falta ou insuficiência de educação, conduta ética, medidas preventivas, dentre outras políticas públicas que poderiam ter evitado o advento da lesão ao ambiente.
} 
nacional e transnacional, os quais devem ser prestados em conjunto com uma imensa quantidade de outras prestações sociais, não é possível impor imediatamente aos poderes públicos a execução ideal e simultânea de todas estas políticas públicas: saneamento básico, educação ambiental, criação e gestão de áreas protegidas, implementação dos tratados internacionais, exercício efetivo de poder de polícia ambiental, dentre outras. Até mesmo pelas naturais limitações fáticas e econômicas.

Porém as limitações fáticas e orçamentárias não podem ser postas como justificativa geral para a inércia na implementação das políticas públicas ambientais previstas de forma completa na Constituição. Por isso, é fundamental a análise criteriosa dos dados empíricos do caso concreto para a justificação das decisões implementadoras de direitos fundamentais prestacionais. A intervenção jurisdicional na condução política das opções do Estado em prol do ambiente alcançará legitimidade quando estiver lastreada na riqueza de dados concretos do caso analisado.

A imposição de medidas positivas pelo Poder Judiciário à administração está plenamente legitimada até mesmo pelas razões que justificaram historicamente a separação entre os poderes. Merece destaque ainda que a vinculação do administrador aos preceitos normativos constitucionais que não apenas limitam as escolhas e opções do administrador como também o obrigam a agir.

A separação das funções estatais ou dos poderes encontra como fundamento ético e jurídico exatamente a contenção do arbítrio ou abuso estatal em detrimento dos direitos humanos. Assim, quando o Poder Judiciário impõe condutas à Administração Pública exatamente para que a omissão não lese direitos humanos fundamentais, como é o caso da proteção ao meio ambiente, não há qualquer ilegitimidade nesta intervenção. Ao contrário, o controle das omissões injurídicas está respaldada nas razões legitimantes da separação dos poderes estatais.

Para a legitimidade da decisão em matéria de controle das políticas públicas ambientais, não é suficiente o esforço argumentativo e retórico no plano abstrato da norma, isso, aliás, é muito mais incumbência do legislador infraconstitucional. A justificação retórica, generalista e abstrata, aliás, não 
demanda maiores esforços argumentativos. Ninguém questiona que é dever do Estado promover a defesa e a proteção do meio ambiente e que este bem supremo garante, em última análise, a própria vida, assegura a dignidade humana. O que é realmente imprescindível para a legitimidade da sindicabilidade dos atos e das omissões do Estado em matéria ambiental é a compreensão e a justificação adequada da norma contexto, ou seja, da norma fundamental construída para o caso concreto de acordo com o contexto fático da demanda, da riqueza de dados do caso concreto, da realidade atualizada dos programas estatais e do status de desenvolvimento econômico e social dos entes federativos envolvidos diretamente na política pública analisada.

A realização de audiências judiciais mais democráticas e participativas é uma das principais estratégias que deverão ser implementadas para legitimar a intervenção forte do Poder Judiciário no âmbito das Políticas Públicas ambientais. Todavia, conforme adverte Gisele Cittadino (2002, p. 17-42) convém advertir que o processo de judicialização da política não depende de uma atuação paternalista do Poder Judiciário, mas, sobretudo, de uma cidadania juridicamente participativa que pode ser exercida também por intermédio de outros instrumentos de controle social previstos na Constituição.

Quase todas as constituição contemporâneas indicam uma ampla lista de tarefas que devem ser implementadas pelo Estado. Trata-se de normas de eficácia plena que estabelece um enorme catálogo de políticas públicas que devem ser implementadas em prol da defesa e proteção do meio ambiente. Hoje o tema do ambiente já está constitucionalizado em muitos países e nestes não há mínima dúvida no sentido de que já há um mínimo exigível do administrador em termos de implementação de políticas públicas ambientais.

Assim, a atuação/intervenção do Poder Judiciário, na execução e na avaliação das políticas públicas ambientais, é plenamente possível em função da forma de positivação constitucional deste direito/dever fundamental. Já há densidade normativa suficiente para a sua concretização efetiva da tutela do ambiente independentemente da superveniência de interposição legislativa.

Pelo exposto, pode-se especular que o controle jurisdicional da correção das políticas públicas ambientais é um dever do Poder Judiciário. Dever este que deve ser exercido na perspectiva intervencionista e transformadora para a 
emancipação do homem na sociedade, para o seu pleno desenvolvimento humano e para a consolidação da justiça social e ambiental.

\section{CONSIDERAÇÕES FINAIS}

O descompasso muitas vezes existente entre os reclamos sociais por justiça e as respostas dadas pelo Poder Judiciário exigem a adoção de novas iniciativas. Medidas estas que promovam uma revolução positiva nas alternativas procedimentais e também uma revitalização hermenêutica para melhor compreensão dos principais institutos da dogmática tradicional relacionados com a tutela do meio ambiente.

A luta obstinada por Justiça Ambiental deve ser um compromisso de todos, em especial das autoridades incumbidas da importante função de julgar e construir justiça. Não se trata de mera utopia ou de um sonho ingênuo, mas de algo que deve e pode ser construído com atitudes, iniciativas concretas, muito idealismo e especial sensibilidade ecológica e social.

A luta por acesso à justiça ambiental no Século XXI será, provavelmente, tão ou mais importante que a luta para garantir os direitos de propriedade dos séculos XIX e XX. (RIFKIN, 2010, p. 533)

O Poder Judiciário, enquanto guardião da ordem constitucional deve atuar numa perspectiva intervencionista e transformadora para a emancipação do homem na sociedade, para o seu pleno desenvolvimento humano e para a consolidação da justiça social e ambiental. Este ideal somente será alcançado com uma hermenêutica comprometida com a atual conjuntura mundial..

O ponto de partida dessa atividade construtiva deve acontecer a partir dos princípios fundamentais da solidariedade e da sustentabilidade. A solidariedade é o componente axiológico imprescindível para a adequada atribuição dos deveres fundamentais e para compreensão da ampla relação pública ambiental que envolve os seres humanos, a comunidade de vida e as futuras gerações.

A sustentabilidade é uma categoria em pleno desenvolvimento e que necessita de mais juridicidade, pois deverá se consolidar enquanto novo paradigma do direito. Trata-se do princípio reitor do qual emergem todos os demais relacionados com a tutela do ambiente. Serve como referente 
hermenêutico indispensável, por contemplar a necessária relação entre as diversas dimensões que interagem no caso concreto: ecológica, econômica, social e tecnológica.

A garantia de uma ordem jurídica ambiental justa depende de um novo modelo de desenvolvimento que interiorize a proteção ambiental como objeto central de preocupação. Para o alcance deste objetivo também é fundamental a institucionalização dos deveres fundamentais, em especial do dever do proprietário de respeitar a função ecológica da propriedade. Afinal, imputar deveres fundamentais pela jurisdição é também uma importante estratégia de gestão do risco para a garantia de um futuro mais solidário e promissor para as futuras gerações.

As decisões e as escolhas do presente é que definirão a qualidade da vida urbana no futuro. Assim, a jurisdição ambiental deve atuar como importante instância de gestão do risco para assegurar um desenvolvimento menos excludente e mais seguro, democrático e sustentável. O principal conjunto de decisões relacionadas ao ambiente envolve a atuação dos Poderes Públicos, os quais também devem exercer de forma efetiva o poder de polícia ambiental. Nesta perspectiva, é fundamental que o Judiciário exerça, com firmeza e responsabilidade, o controle da implementação do amplo conjunto de políticas públicas previstas nos ordenamentos jurídicos em prol da proteção e defesa do meio ambiente.

Como observado, o efetivo acesso a justiça ambiental não é só procedimento, diz respeito principalmente às dimensões materiais da jurisdição, ou seja, a adequada compreensão dos seus princípios estruturantes e institutos diretamente relacionados com o comportamento humano e as suas influências no entorno.

O sistema de processo coletivo da tutela do ambiente podem propiciar decisões mais eficazes, desde que os institutos processuais sejam interpretados em sintonia com os princípios ambientais e com a superação da lógica de pensamento do processo clássico destinado à tutela dos bens individuais. Dentre os princípios merece especial destaque o da participação, ou seja, o envolvimento ativo do cidadão e na dialética construtiva e revitalizada do processo, pois é o principal destinatário do resultado da prestação jurisdicional. 
Afinal, a verdadeira justiça ambiental é aquela que, além de significar a solução justa para o caso concreto, também produz efeitos no plano da coexistência pessoal e ecológica, isso porque ao conter uma mensagem pedagógica contundente, contribui com a melhora contínua das relações entre as pessoas e destas com a natureza.

\section{REFERÊNCIAS BIBLIOGRÁFICAS}

ALEXY, Robert. El concepto y la validez del derecho. 2. ed. Barcelona: Gedisa, 1997.

ARNAUD, André-Jean. Entre modernité et mondialisation: Leçons d'histoire de la phisosophie du droit et de l'État. 2. ed. Paris: L.G.D.J, 2004

BECK, Ulrich. A reinvenção da Política: rumo a uma teoria da Modernização Reflexiva. In: BECK, Ulrich; GIDDENS, Anthony; LASH, Scott. Modernização reflexiva: política, tradição e estética na ordem social moderna. Trad. Magda Lopes. São Paulo: UNESP, 1997

BENJAMIN, Antônio Herman. A insurreição da aldeia global contra o processo civil clássico - apontamentos sobre a opressão e a libertação judiciais do meio ambiente e do consumidor. In: MILARÉ, Édis (Org.). Ação Civil Pública: Lei 7.347/85 reminiscências e reflexões após dez anos de aplicação. São Paulo: Revista dos Tribunais, 1995.

BRASIL. Supremo Tribunal Federal. Medida Cautelar na Ação Direta de Inconstitucionalidade 3540. Relator Ministro Celso de Melo. Disponível em: <www.stf.gov.br >. Aceso em 18 jun. 2011.

BODNAR, Zenildo; CRUZ, Paulo Márcio. A possibilidade da justiça transnacional na globalização democrática. Revista Novos Estudos Jurídicos, Itajaí, v. 15, n. 3, p. 432-446, 2010.

BOSSELMANN, Klaus. The principle of sustainability: Transforming law and Governance. New Zealand: ASHAGATE, 2008.

CAPPELLETTI, Mauro; GARTH, Bryant. Acesso à Justiça. Trad. Ellen Gracie Northefleet. Porto Alegre: SAFE, 1988.

CAVEDON, Fernanda Salles. Renovação do sistema jurídico-ambiental e realização do acesso à Justiça Ambiental pela atividade criadora no âmbito da decisão judicial dos conflitos jurídico-ambientais. Tese de Doutorado defendida junto à Universidade do Vale do Itajaí, 2006. 
CITTADINO, Gisele. Judicialização da política, constitucionalismo democrático e separação de poderes. In: VIANNA, Luiz Werneck (org.). A democracia e os Três Poderes no Brasil. Belo Horizonte: UFMG, Rio de Janeiro: IUPERJ/FAPERJ, 2002.

COLL, Amengual Gabriel. La moral como derecho: Estudio sobre la moralidad en la Filosofia del Derecho de Hegel. Madrid: Trotta, 2001.

CORDINI, Giovanni. Diritto Ambientale Comparato. Padova: CEDAM, 1997.

CRUZ, Paulo Márcio; BODNAR, Zenildo. O novo paradigma de Direito na pósmodernidade - Porto Alegre - RECHTD/UNISINOS. Revista de Estudos Constitucionais, Hermenêutica e Teoria do Direito, v. 3, p. 75-83, 2011.

CUTANDA LOZANO, Blanca. Derecho Ambiental Administrativo. 7. ed. atual. Madrid: Dykinson, 2006.

ESTEVE PARDO, José. Técnica, Riesgo e Derecho: tratamiento del riesgo tecnológico en el Derecho Ambiental. Barcelona: Ariel, 1999.

FARIA, José Eduardo. Justiça e Conflito. Os juízes em face dos novos movimentos sociais. 2. ed. rev. e ampl. São Paulo: Revista dos Tribunais, 1992.

FREITAS, Juarez. Sustentabilidade: direito ao futuro. Belo Horizonte, Editora Fórum, 2011.

FREITAS, Vladimir Passos de (Org.) Direito ambiental em evolução. Curitiba: Juruá, 1998.

GOLDBALTT, David. Teoria Social do Ambiente. Lisboa: Piaget, 1996.

MARTÍN MATEO, Ramón. La revolución ambiental pendiente. In: PIÑAR MAÑAS, José Luis. Desarrollo Sostenible y protección del medio ambiente. Civitas: Madrid, 2002.

MIRRA, Álvaro Luiz Valery. Ação Civil Pública e a Reparação do Dano ao Meio Ambiente. São Paulo: Juarez de Oliveira, 2002.

LEITE, José Rubens Morato; AYALA, Patryck de Araújo. Direito Ambiental na Sociedade de Risco. Rio de Janeiro: Forense Universitária, 2002.

NALINI, José Renato. O futuro das profissões jurídicas. São Paulo: Oliveira Medes, 1998.

PÉRES CONEJO, Loreno. La defensa judicial de los intereses ambientales. Estúdio específico de la legitimación 'difusa' em el processo contenciosoadministrativo. Valladolid: Lex Nova, 2002. 
PRIEUR, Michel. O Direito do Ambiente na França. In: AMARAL, Diogo Freitas e ALMEIDA, Márcia Tavares (Coords.). Direito do Ambiente. Lisboa: INA Instituto Nacional de Administração. 1994.

REAL FERRER, Gabriel. El derecho ambiental y los derechos de la tierra. Madrid: Revista Temas (www.sistemadigital.es/pubs/magazine.aspx?ID=3), febrero de 2011, número 195.

RIFKIN, Jeremy. La civilización empática: la carrera hacia una conciencia global em um mundo en crisis. Trad. de Genís Sánches Barberán y Vanesa Casanova. Barcelona: Paidós, 2010, p. 533.

TATE, Neal C.; VALLINDER, Torbjörn. The Global Expansion of Judicial Power: the judicialization of politics. In: TATE, Neal C.; VALLINDER, Torbjörn (Orgs.) The Global Expansion of Judicial Power. New York: New York University Press, 1995.

TEUBNER, Gunther. A Bukowina Global sobre a emergência de um pluralismo jurídico transnacional. Piracicaba: Revista de Ciências Sociais e Humanas, 2003.

SARLET, Ingo Wolfgang. Direitos fundamentais e proporcionalidade: notas a respeito dos limites e possibilidades da aplicação das categorias da proibição de excesso e de insuficiência em matéria criminal. Revista da AJURIS, v. 35, n. 109, mar. 2008, p. 142/143.

SERRANO, José Luis. Principios de Derecho Ambiental e Ecologia Juridica. Madrid: Trotta, 2007.

VARELLA. Marcelo Dias. A Dinâmica e a Percepção Pública de Riscos e a Resposta do Direito Internacional Econômico. In: VARELLA. Marcelo Dias (Org.). Governo dos Riscos. Brasília: UNICEUB, 2005.

VIANNA, Luiz Werneck [et al.]. A judicialização da política e das relações sociais no Brasil. Rio de Janeiro: Revan, 1999.

WARAT, Luis Aberto. A rua grita Dionísio! Direitos humanos da alteridade, surrealismo e cartografia. Rio de Janeiro: Lúmen Júris, 2010.

WEISS, Edith Brown. Un mundo Justo para las Futuras Generaciones: Derecho Internacional, Patrimonio Común y Equidad Integeracional. Trad. Máximo E. Gowland. Madrid: United Nations, Mundi-Prensa, 1999. 